\title{
Small States, Micro States, and their International Negotiation and Migration
}

Maurice Schiff

IZA-Institute for the Study of Labor, Washington DC, USA

\begin{abstract}
Due to low bargaining power and scarce resources, small developing states face severe disadvantages in international negotiations and may benefit from bloc formation and intra-bloc migration. Policies are examined in a model where a bloc's size and welfare impact are determined by international and regional negotiation costs, bargaining power, accession rule, and intra-bloc migration. The main findings are: (i) bloc formation likelihood, size, and benefit increase with international negotiation costs; (ii) intra-bloc migration acts as a public good, raising regional benefits; (iii) bloc size is optimal in the presence of accession fees; (iv) intra-bloc migration and NorthSouth trade are complements under negotiations for increased market access. Thus, even if trading identical goods, small neighboring states should consider forming an international negotiating bloc and supporting intra-bloc migration.
\end{abstract}

JEL Classifications: F11, F15, F22

Key words: Small States, International Negotiations, Regional Cooperation, SouthSouth Migration, Bloc Size, Welfare

\footnotetext{
* Corresponding Author: Maurice Schiff; IZA-Institute for the study of Labor, K st NW Apt 501, 3299 Washington DC, USA; Tel: +202 338879, E-mail: schiffmaurice@yahoo.com.

Acknowledgements: I would like to thank David Argente and participants in the International Trade Unit Seminar series of the World Bank Development Economics Research Group for their useful comments. This paper was initiated while the author was at the World Bank. It reflects the author's views and not necessarily those of the World Bank, its Board of Executive Directors, or the governments they represent.
} 


\section{Introduction}

Small and micro states are countries comprised with less than one and a half and less than one million inhabitants defined by the UN, respectively. They face severe disadvantages in dealing with the rest of the world because of their low bargaining power and limited financial and human resources for the various international negotiations. By forming a regional cooperation agreement and negotiating as a bloc, small and micro states could benefit from greater bargaining power and visibility as well as from lower international negotiation costs. ${ }^{1}$ As the world has become more integrated, the number of issues to be dealt with in the international arena has grown and so has the importance of regional cooperation among these states.

Regional blocs consisting of small or micro developing states have typically arisen within specific geographic regions as member countries tend to exhibit greater similarity of interests than more distant countries. They are more likely to produce similar products, have similar historical experiences, share the use of public goods, and negotiate with the same regional or global powers. An example of such a bloc is the fifteen-member Caribbean Community or Caribbean Community and Common Market (CARICOM), consisting of twelve micro states, one small state, and two larger countries (Haiti and Jamaica), thirteen of which are Anglophone (Dutch is spoken in Suriname, French in Haiti). Another regional bloc is the Organization of Eastern Caribbean States (OECS), which consists of micro states, most of which are also members of CARICOM but are more closely integrated. These states are either former colonies or overseas territories of the UK and exhibit close historical, economic, and cultural ties including a common currency, i.e., the East Caribbean dollar, and English as a common language. A third example is the twelve-member Pacific Island Countries Trade Agreement (PICTA), which comprises eleven micro states and one larger country, Papua New Guinea.

Byron (1994) and Inter-American Development Bank (IADB) (1995) argue that, in accordance with one of CARICOM's objectives, its members have pooled their negotiation resources and negotiated as one bloc with larger countries, blocs, and organizations in the region and elsewhere. ${ }^{2}$ Specifically, CARICOM has been involved

\footnotetext{
${ }^{1}$ Andriamananjara and Schiff (2001) consider such motivation for bloc formation, though not the trade and migration-related issues examined in this paper.

${ }^{2}$ See also Ffrench-Davis (1979) on the gains from joint negotiations with third parties.
} 
in negotiations with the World Trade Organization (WTO), the Commonwealth, the United Nation Conference on Trade and Development (UNCTAD), and the UN Conference on the Laws of the Sea, and has participated in various commissions with Canada, the US, Japan, the Free Trade Area of the Americas (FTAA), the Organization of American States (OAS), and the G3 (Colombia, Mexico, Venezuela). It has also negotiated an Economic Partnership Agreement (EPA) with the European Union (EU) and preferential agreements with, for instance, Colombia, Costa Rica, the Dominican Republic, and Venezuela. Moreover, CARICOM nations have succeeded in getting their nationals elected to key international positions such as Commonwealth SecretaryGeneral and the African, Caribbean and Pacific Group of States (ACP) SecretaryGeneral. $^{3}$

Increasing intra-bloc trade does not seem to have been a major goal underlying the creation of CARICOM. In fact, CARICOM was associated with a constant level of intra-bloc trade and a constant or declining share of intra-bloc trade in its total trade. Schiff and Winters (2003) examined CARICOM's intra-bloc trade one year before its formation (1972) and five years after it (1978) and found that the share of intrabloc imports in total imports fell from 5\% to $3.8 \%$ (a 24\% decline), its intra-bloc trade intensity fell from 13.6 to 7.7 (a 44\% decline) and its intra-bloc trade propensity fell from 7.5 to 6.2 (a 17\% decline). As for later periods, Martinez-Zarzoso (2000) found little, if any, impact of CARICOM on the level of bilateral intra-bloc trade for the 1980s and 1990s, and te Velde (2008) found that CARICOM had no impact on the level of intra-bloc trade for a longer sample period (1970 2004). ${ }^{5}$ These studies seem to confirm Byron's (1994) and IADB's (1995) findings that increasing intra-bloc trade was not one of the main objectives underlying the formation of CARICOM.

Though regional bloc members may benefit from greater bargaining power and sharing international negotiation costs, they must engage in regional negotiations in

\footnotetext{
${ }^{3}$ The analysis applies also to regional bloc member states whose population is larger 1.5 million - and which are thus not small or microstates according to the UN definition - but which nevertheless have little influence in international negotiations with developed countries or regions. For instance, such states' imports and exports might be small in comparison with the rest of the world and they would therefore have little if any influence on the prices paid for their imports or received for their exports. Such regional blocs might include West African Economic and Monetary Union (WAEMU) or (average population: 12 million; average 8.5 billion US dollars, CAFTA (8 million; 27 billion US dollars), the East African Community (25 million; 15 billion US dollars), and others. Of course, exports of a given commodity in some individual member country might be sufficiently large to affect world prices, an example of which would be cocoa exports from Côte d'Ivoire, a member of WAEMU.

${ }^{4}$ She used a gravity model to estimate the impact of the EU, NAFTA, CARICOM, CAFTA and other blocs on intra-bloc trade in 1980 1999 and in sub-periods. She finds that CARICOM had (i) a positive impact in the earliest period 1980 1984, (ii) non-significant impacts in the periods 1985 1989, 1990 1994 and 1995 1999, and (iii) a non-significant impact over the twenty-year period 1980 1999.

${ }^{5}$ Neither did it contribute to member countries' growth rate, or $\sigma$-convergence or $\beta$-convergence of member countries' incomes.
} 
order to reach common positions on the various issues. Such negotiations entail costs which increase with the extent of heterogeneity of member countries' initial positions and with the number of member states, costs which do not arise under individual negotiations.

An issue that has not been examined in this context is that of international migration. International migration could make a significant contribution by raising the likelihood of a regional bloc being formed as well as raising the benefit obtained from it. Its contribution is particularly important when distance between member states is small and their degree of heterogeneity is large.

Classic papers in the trade literature dealing with international migration or with international factor movement are Mundell (1957) and Markusen (1983). The Mundell paper uses a Heckscher-Ohlin model to show that trade and factor movements are substitutes, while Markusen shows that assuming identical endowments and changing any one of the other Heckscher-Ohlin model's assumptions result in complementarity. These studies do not examine the impact of differences in trading partners' level of development though later studies do. For instance, de Melo (2007) looks at political economy aspects of South-North migration, trade and Foreign Direct Investment (FDI), and de Melo and Ivlevs (2008) examine economic aspects of these relationships.

Migrations between developing countries also take place because of the higher cost of South-North migration. López and Schiff (1998) examine these issues in an extended Heckscher-Ohlin model where financing constraints are binding for unskilled but not for skilled migrants. They find that trade and migration are substitutes for skilled labor and complements for unskilled labor. The financing constraint hypothesis seems to be supported by Ozden et al.'s (2009) findings that 47\% of all migration from the South was to the South in 2000 and over $80 \%$ of it was to a neighboring country.

A large number of studies in the migration literature have looked at other determinants of international migration. For instance, Mora and Taylor (2006) examined the impact of individual, household, and community characteristics. Bollard et al. (2009) used micro data to examine the relationship between migrants' human capital and their remittance level. Migrant networks also have a positive impact on trade (Rauch 1999) and on FDI (Javorcik et al. 2010, Kugler and Rapoport 2007), implying that migration is complementary with both. A number of papers (Beine et al. forthcoming, Mora and Taylor 2006) have also found that, by reducing migration costs and raising benefits, migrant networks have a large positive impact on migration and a negative selection effect with respect to education. McKenzie and Rapoport (forthcoming)examined 
the impact of migrant networks from a large sample of Mexican municipalities and obtained similar results.

This paper presents a model in which bloc formation by a region's small and micro developing states (henceforth referred to as small states) is based on negotiation costs and bargaining power rather than on the traditional trade-related basis for regional integration. ${ }^{6}$ It also provides a different motive for migration, which acts as a public good.

The questions examined here are: (i) Can small states gain by forming a regional bloc for cooperation on international negotiations? How large are they? (ii) How do different rules of accession to the bloc affect bloc size and member states' benefits? (iii) Can intra-bloc South-South migration raise the bloc's welfare gains? (iv) What is the relationship between intra-bloc migration and North-South trade?

The rest of the paper is organized as follows. Section II presents a general equilibrium framework in order to examine the formation of a regional cooperation bloc among small states and its welfare implications under two accession rules. Section III examines the impact of South-South migration. Section IV looks at the relationship between migration and trade. Finally, Section V concludes.

\section{The Model}

Subsection A presents a general equilibrium framework in order to analyze the formation of a regional cooperative arrangement or regional bloc among some of the region's small states. Subsections B and C examine the bloc's equilibrium size and welfare impact under two different rules regarding small states' accession to the regional bloc. This section abstracts from international migration, which is taken up in Section III.

${ }^{6}$ An early version of this paper is Schiff (2010). 


\section{A. Bloc formation in a general equilibrium framework}

Assuming that a Heckscher-Ohlin model for a region consisting of small developing states $i \in(0,1]$ and producing a labor-intensive good is $X$ and a capital-intensive good is $Y$, the small states are relatively labor abundant in comparison to their trading partner in the North. Hence, they export $X$ to and import $Y$ from the North, with imports taking place under free trade conditions. Their labor-to-capital ratio $\left(L_{i} / K_{i}\right) \in(0,1]$ is distributed uniformly, and capital is assumed to be immobile internationally. The region's small states and the region as a whole, take world prices as given and pursue free trade policies or have identical trade barriers, thus exhibiting identical goods and factor prices. Hence, they have no incentive to trade with each other and individuals have no incentive to migrate from one small state to another.

The Heckscher-Ohlin model is not solved explicitly as the qualitative impact of different types of international negotiations on output, trade, and trade-migration relationship can be derived without it. The Heckscher-Ohlin model is augmented with (i) negotiations between the region's small states and the North, (ii) formation of a cooperative bloc by some of the region's small states, and (iii) intra-bloc migration. Internal solutions are assumed throughout unless stipulated otherwise. Each bloc member's revenue $(R)$ from collective action is

$$
R=R(n), R_{n} \equiv \partial R / \partial n>0, R_{n n} \equiv \partial^{2} R / \partial n^{2}<0
$$

with bloc size $n \in(0,1)$ distributed uniformly. The $R(n)$ increase with $n$ reflects the fact that a bloc's bargaining power in international negotiations increases with its size, and that foreign entities that might be unwilling to negotiate with each one of the region's small states individually might do so with a bloc because of lower negotiating costs and the region's greater visibility.

Negotiation costs are of two types: international costs and regional costs. A small state negotiating individually incurs the international negotiation cost $x$. The international negotiation cost incurred by each member of an $n$-country regional bloc is:

$$
C^{I}=C^{I}(n, x), C_{n}^{I}<0, C_{n n}^{I}>0, C_{x}^{I}>0, C_{n x}^{I}<0
$$


Bloc members also incur a regional cost for reaching a common position which is given by

$$
C^{R}=C^{R}(n, \alpha), C_{\alpha}^{R}>0, C_{\alpha \alpha}^{R}>0 ; C_{n}^{R}>0, C_{n n}^{R}>0 ; C_{n \alpha}^{R}>0^{7}
$$

where $\alpha$ represents the degree of heterogeneity in member states' negotiating positions, which is assumed to be a function of the heterogeneity in their relative endowments of labor and capital or labor-capital ratios.

$C^{R}$ increases with $\alpha$ at an increasing rate, implying that a degree of heterogeneity exists beyond which it is preferable to negotiate individually than as part of a regional bloc, in which case no such bloc is formed. $C^{R}$ also increases at an increasing rate with bloc size $n$ which, together with Equations (1) and (2), implies that a bloc size exists beyond which bloc members lose from the accession of additional countries, and a larger bloc size exists where it is more beneficial to negotiate individually. These are solved for in Subsection B and C.

The solution provided in the sections below assumes that bloc members minimize regional negotiation costs $C^{R}$ by minimizing the heterogeneity of their labor-capital ratios $L_{i} / K_{i} \in(0,1)$. Assuming a uniform distribution of $L_{i} / K_{i}$, heterogeneity is minimized when the $n$ bloc members' $L_{i} / K_{i}$ ratios form a continuum, so that $L_{i} / K_{i} \in(y, y+n), y \in[0,1-n]$.

The total negotiation cost is the sum of the international and regional costs or

$$
C(n, x, \alpha)=C^{I}(n, x)+C^{R}(n, \alpha)
$$

The average (net) benefit, $B$, of membership in the bloc is defined as the difference between the average gross benefit $R(n)-C^{I}(n, x)-C^{R}(n, \alpha)$ and the gross benefit of negotiating individually or $B^{1}(x)=R(1)-x$. Thus, $B$ is given by

$$
B(n, \alpha, x)=R(n)-C^{I}(n, x)-C^{R}(n, \alpha)-B^{1}(x)
$$

Since $R(n),-C^{I}(n, x)$ and $-C^{R}(n, \alpha)$ are concave in $n$, so is $B$; i.e., $B_{n n}<0 .{ }^{8}$

An example of Equation (2) is $C^{I}=x / n$, and an example of Equation (3) is $C^{R}=\alpha^{2} n^{2}$.

${ }^{8}$ Note that $R$ need not be concave as long as $B_{m n}<0$. 
The bloc's total benefit or value is $V(n, \alpha, x)=n B(n, \alpha, x)$.

A bloc's equilibrium size is likely to depend on its accession rule. Two such rules are examined. The first one, Subsection B assumes that existing member states do not charge an accession fee. The second one, Section III assumes they do if it is optimal.

\section{B. No accession fee}

The bloc expands as long as the average benefit $B$ increases; i.e., until the maximum value $B=B^{E}$ is reached, with $B_{n}=R_{n}-C_{n}=0\left(B_{n n}<0\right.$ satisfies the second-order condition). Since $V_{n}=B+n B_{n}$, it follows that at the optimum, $V_{n}=B$, or the bloc's marginal value, equals its average value.

Figure 1. Average and Marginal Bloc Benefit, With and Without Intra-bloc Migration, and With and Without Accession Fee

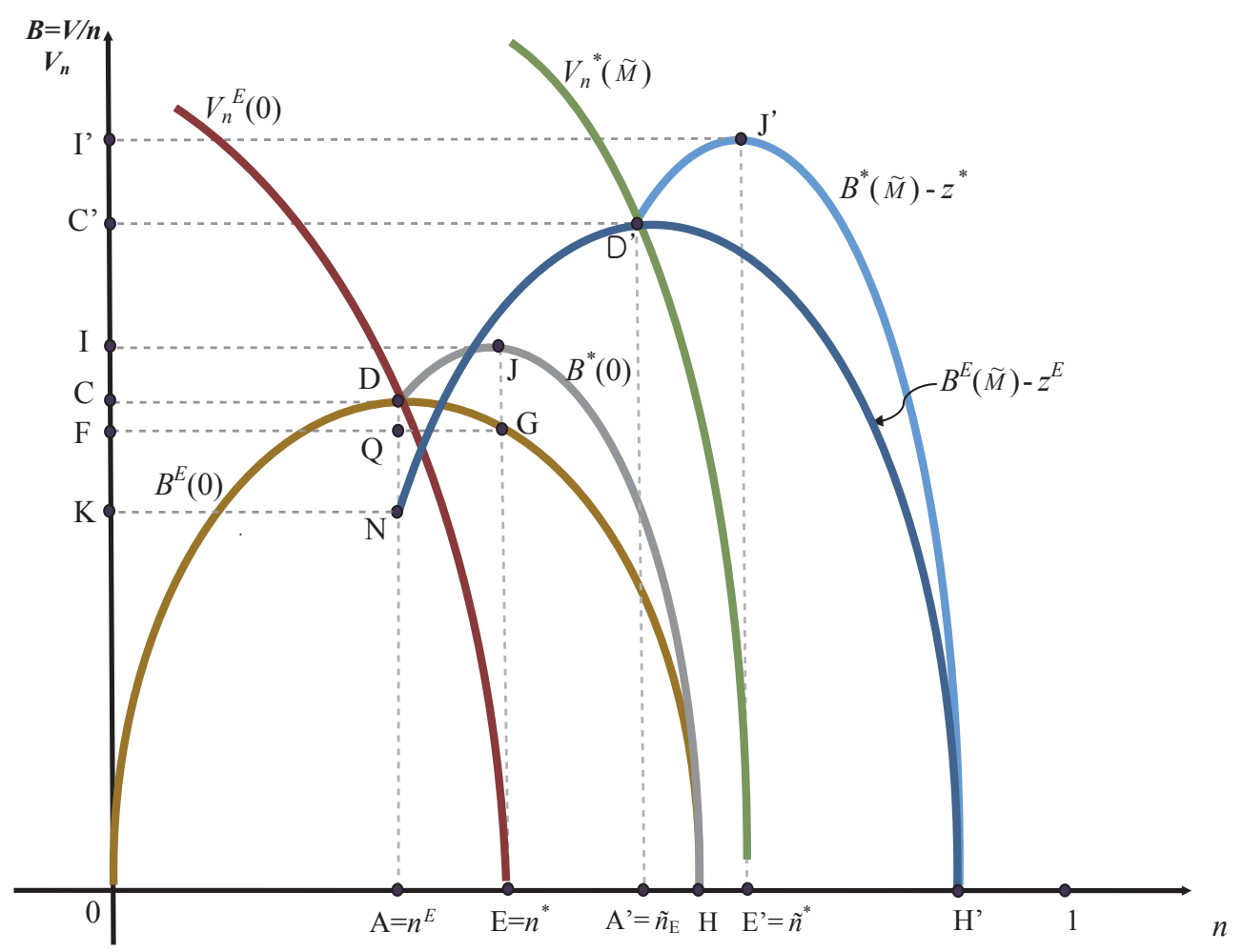


The solution, denoted by the pair $n^{E}$ and $B^{E}$, is represented by point $\mathrm{D}$ on the average benefit curve $B^{E}(0)$ in Figure $1,{ }^{9}$ and the optimal bloc size $n=n^{E}$ is represented by point A. The marginal and average benefit curves $V_{n}(0)$ and $B(0)$ intersect at $n=n^{E}$ where $V_{n}=B^{E}$ is given by $\mathrm{DA}=\mathrm{C} 0$. The value of the bloc is $V^{E}=n^{E} B^{E}$ and is given by the area COAD. It also constitutes the region's welfare gain from the formation of the bloc.

If heterogeneity, $\alpha$, is greater than critical value $\hat{\alpha}^{E}$ where $B^{E}=0$; i.e., if regional negotiation costs are so high that the bloc's welfare impact is negative, no regional bloc will arise. In what follows, it is assumed that $\alpha<\hat{\alpha}^{E}$ and an internal solution is obtained.

The total differential of the first-order condition $B_{n}=R_{n}-C_{n}=0$ is $B_{n n} d n-C_{n x}^{I} d x-$ $C_{n \alpha}^{R} d \alpha=0$. Together with $B_{n n}<0, C_{n \alpha}^{R}>0, C_{n x}^{I}<0$ (from [1] to [3]), it implies

$$
\frac{d n^{E}}{d \alpha}=\frac{C_{n \alpha}^{R}}{B_{n n}}<0, \frac{d n^{E}}{d x}=\frac{C_{n x}^{I}}{B_{n n}}>0
$$

Thus, bloc size $n^{E}$ that maximizes member states' average benefit falls with their level of heterogeneity — and thus with regional negotiation costs — and increases with international negotiation costs.

\section{Accession fee}

In this case, the $n^{E}$ member states allow additional states to accede to the bloc if it raises their benefits. Non-member states are willing to join the bloc and pay an (implicit) accession fee as long as their net accession benefit $B^{I}$ is non-negative, and, given the excess-supply of aspiring members under internal solution, the solution for the net benefit is $B^{I}=0 .{ }^{10,11}$ Consequently, the benefit for the $n^{E}$ member states of new members' accession is given by $V / n^{E}=n B / n^{E}$, where $B$ is a function of $n$. Since $n^{E}$ is

\footnotetext{
${ }^{9}$ Figure 1 shows four average and two marginal benefit curves. The two average benefit curves in the absence of migration, located on the left-hand side of Figure 1, are denoted by $B^{E}(0)$ in the absence of accession fee (Equation (5)) and $B^{*}(0)$ in its presence and $V_{n}^{E}(0)$ is the corresponding marginal benefit curve for both. In the case of migration, the two average benefit curves, located on the right-hand side of Figure 1 , are denoted by $B^{E}(\tilde{M})-z^{E}$ in the absence of accession fee and by $B^{*}(\tilde{M})-z^{*}$ in its presence, and $V_{n}^{*}(\tilde{M})$ is the corresponding marginal benefit curve for both. The average benefit curves $B^{*}(0)$ and $B^{*}(\widetilde{M})-z^{*}$ are defined in Subsection C and Section III, respectively.

${ }^{10}$ Given that $\alpha<\hat{\alpha}^{E}$ and $\hat{\alpha}^{E}<\hat{\alpha}^{*}$, it follows that $\alpha<\hat{\alpha}^{*}$ and an internal solution obtains.

${ }^{11}$ If the total number of small states is smaller than $n^{*}$, i.e., $n^{*}>1$ (a corner solution), the new members are likely to obtain a benefit $B>B^{I}$ whose value depends on their number $\left(1-n^{E}\right)$ and on their bargaining power relative to that of the $n^{E}$ insider countries.
} 
given, it follows that the maximand in this case is the total benefit $V$ or the average benefit for the $n^{E}$ members, rather than the average benefit $B$ for all $n^{*}$ members. At $n^{E}, V_{n}=B^{E}>B^{I}=0$ and the $n=n^{E}$ member states have an incentive to allow additional members to accede.

The optimum bloc size is $n=n^{*} \in\left(n^{E}, 1\right)$ where the marginal benefit $V_{n}=0$; i.e., where $V_{n}=B+n B_{n}=B\left(1+\varepsilon_{B . n}\right)=0$ or $\varepsilon_{B . n}=-1$, where $\varepsilon_{B . n}$ is the elasticity of average benefit with respect to bloc size $n$. The optimum size is represented by point $\mathrm{E}$ in Figure 1 where $n=n^{*}$. The corresponding average benefit $B=B^{*}$ is represented by point $\mathrm{G}$ on curve $B(0)$ and by point $\mathrm{J}$ on curve $B^{*}(0)$. Note that the elasticity at point $\mathrm{G}$ is minus one $\left(\varepsilon_{B . n}=-1\right)$. The average benefit $B^{*}$ at point $\mathrm{G}$ is represented by $\mathrm{GE}=\mathrm{F} 0$ and the bloc value $V^{*}=n^{*} B^{*}$ is represented by area F0EG. The increase in the value of the bloc, $V^{*}-V^{E}$, is given by the area EAD. The bloc also maximizes welfare for the region as a whole in this case since the marginal net benefit is equal to zero for all three country groups, namely the $n^{E}$ original bloc members, the $\left(n^{*}-n^{E}\right)$ additional bloc members, and the $\left(1-n^{*}\right)$ non-members.

I now turn to equilibrium point $\mathrm{J}$. The average benefit, $B$, is defined as the value of the bloc, $V=n B$, divided by the number of bloc members, $n$. Thus, the average benefit $B^{*}$ at $n=n^{*}$ is equal to $V^{*} / n^{*}$, which is represented by point $\mathrm{G}$ in Figure 1 . Since the original $n^{E}$ members aim to maximize their average benefit, one could alternatively define the average benefit as the value of the bloc per original member, $B_{O R}$; i.e., as $B_{O R}$ $\equiv V(n) / n^{E}=n B / n^{E}>B$ for $\forall n \in\left(n^{E}, 1\right)$. Since $n^{*}>n^{E}$, it follows that $V(n) / n^{E}>V(n) /$ $n$ for $\forall n \in\left(n^{E}, 1\right)$. The locus of $B_{O R}$ is represented by the curve $B^{*}(0)$ in Figure 1. Its maximum value, $B_{O R}^{*}=V^{*} / n^{E}=n^{*} B^{*} / n^{E}>B$, is represented by point $\mathrm{J}$, with $B_{O R}^{*} / B^{*}=n^{*} /$ $n^{E}>1$ equal to JE/GE $=\mathrm{E} 0 / \mathrm{A} 0$. The accession fee leads to an increase in the average benefit $\left(B_{O R}^{*}-B^{E}\right) / B^{E}$ for the bloc's original members, with the increase equal to (JE $\mathrm{DA}) / \mathrm{DA}=\mathrm{IC} / \mathrm{C} 0$.

The first-order condition is $V_{n}=B+n B_{n}=0$. From its total differential and Equations (1) to (3), we obtain the impact of $\alpha$ and $x$ on $n^{*}$ through

$$
\frac{d n^{*}}{d \alpha}=\frac{C_{\alpha}^{R}+n^{*} C_{n \alpha}^{R}}{2 B_{n}^{*}+n^{*} B_{n n}}<0, \quad \frac{d n^{*}}{d x}=\frac{C_{x}^{I}+n^{*} C_{n x}^{I}}{2 B_{n}^{*}+n^{*} B_{n n}}>0
$$

Thus, bloc size $n^{*}$ falls with member states' heterogeneity; i.e., $n^{*}$ falls with regional negotiation costs and it increases with international negotiation costs. This result is 
qualitatively identical to that obtained in the absence of accession fee.

Finally, under open access to the bloc, $B=0$ is identical for the region's three country groups, and the value of the bloc is entirely dissipated (as shown by point $\mathrm{H}$ in Figure 1).

The main results obtained in this section are collected in the following proposition.

Proposition 1: Assume that there is a region where some small states engage in international negotiations as a bloc. Denoting the average benefit of such negotiations by $B^{N}\left(B^{E}, B^{*}\right)$, we have:

(i) The likelihood that $B^{N}>0$ and $a$ bloc is formed rises with international negotiation costs and falls with bloc members' level of heterogeneity $\alpha$ (and thus with regional negotiation costs);

(ii) In the absence of an accession fee policy, equilibrium bloc size $n^{E}$ maximizes members' average benefit $B^{E}$ but not regional welfare;

(iii) Under an accession fee policy, equilibrium bloc size $n^{*}>n^{E}$ maximizes the $n^{E}$ members' average benefit at the level $n^{*} B^{*} / n^{E}>B^{E}$ and maximizes regional welfare;

(iv) $\frac{d n^{j}}{d \alpha}<0, \frac{d n^{j}}{d x}>0 ; j=E, *$; and

(v) A bloc that would not be formed in the absence of an accession fee, due to heterogeneity $\alpha$ being greater than the critical level $\hat{\alpha}^{E}$ for which $B^{E}=0$, might still be formed in the presence of an accession fee $\hat{\alpha}^{*}>\hat{\alpha}^{E}$ if $\hat{\alpha}^{E}<\alpha<\hat{\alpha}^{*}$ (and would not be formed if $\alpha>\hat{\alpha}^{*}$ ).

\section{South-South Migration}

While Section II took heterogeneity $\alpha=n^{E}$ to be exogenous, this section assumes it is endogenous and determines its optimal value. The heterogeneity in initial bloc members' positions, which is represented by $\alpha$, is determined by the heterogeneity in

\footnotetext{
${ }^{12}$ The analysis assumes the $\left(1-n^{*}\right)$ non-member states engage in international negotiations individually. Alternatively, non-member states might form one or several new blocs together with the $\left(n^{*}-n^{E}\right)$ bloc members whose gross benefit is also $B^{I}$. Write $1-n^{E}=q n^{E}$ $+r, 0 \leq r<n^{E}$, where $q \geq 0$ is a natural number. Then, $q$ blocs of size $n^{E}$ and one bloc of size $r$ will form. (If $n^{E}>1 / 2$, it means that $q=$ 0 , with $r=1-n^{E}<n^{E}$ ). The average benefit $B^{r}$ in the $r$-bloc is given by $0 \mathrm{~K}$ in Figure 1. Since the marginal benefit for the $n^{E}$-bloc, AD $=0 \mathrm{C}$, is larger than the average benefit for the $r$-bloc, the $n^{E}$-bloc would gain by offering a little more than $0 \mathrm{~K}$ to an $r$-bloc member. However, since marginal benefit in the $r$-bloc is higher than in the $n^{E}$-bloc, bloc size remains unchanged. The same holds for $q>0$ and the alternative assumption of $q>0$ has no qualitative impact on the results.
} 
the uniformly distributed labor-capital ratio $l_{i} \equiv L_{i} / K_{i} \in(0,1]$.

Trade tends to reduce differences in the value of trading countries' endowments. Trade liberalization in the Heckscher-Ohlin model raises (reduces) the labor-to-capital price ratio in the country where it is relatively abundant (scarce). On the other hand, migration reduces differences in the physical quantity of endowments as labor moves from labor-abundant to labor-scarce countries. Moreover, the liberalization of a small host state's immigration policy has no impact on factor prices in the home or source countries unless migration is large enough to lead to specialization in production.

In this section, I examine whether intra-bloc migration can reduce the heterogeneity in labor-capital ratios $\alpha$ and thereby reduce the regional negotiation $\operatorname{cost} C^{R}(n, \alpha, m)$ such that the $n^{E}$ bloc members' benefits increase. ${ }^{13}$ Individuals in those states have no incentive to migrate to other member states as it entails a cost and, with identical wages, no private benefit. Thus, the $n^{E}$ states must decide whether to subsidize intrabloc migration in order to benefit from the positive externalities associated with lower regional negotiation costs, a decision which depends on the level of migration costs. This cost is likely to be small for proximate bloc members; e.g., for members of Caribbean Community and Common Market (CARICOM) or the Organization of Eastern Caribbean States (OECS).

A number of statistics of the distribution of $l_{i}$ can serve as a measure of heterogeneity. For simplicity, heterogeneity is measured here by the range of $l_{i}$ values; i.e., $\alpha=l_{M A X}-l_{M I N}$. Assume, without loss of generality, that $K$ is constant at level $K=1$. Then, $l_{i}$ simplifies to $L_{i}, L_{i} \in(0,1]$ distributed uniformly, with $\alpha=L_{M A X}-L_{M I N}$.

Denote migration by $M$, with $M \in(0,1)$. The optimal way to reduce $\alpha$ is to start with migration from the state with the largest labor force, $L_{M A X}$ (the top state), to the state with the smallest labor force, $L_{\text {MIN }}$ (the bottom state). Since migration reduces the labor force in the top state and raises it in the bottom one, the number of top and bottom states increases with $M$ (with bottom (top) ones having increasingly more (less) labor). Thus, as migration proceeds, a reduction in the value of $\alpha$ requires emigration from, and immigration to, an increasing number of states. In other words, the negative impact of migration on $\alpha$ declines as migration increases; i.e., $\partial \alpha / \partial M<0, \partial^{2} \alpha / \partial M^{2}>0$.

Pre-migration heterogeneity is $\alpha^{0}=n^{E 0}=L_{M A X}^{0}-L_{M I N}^{0}$. The impact of $M$ on $\alpha$ is $\partial \alpha / \partial M=-4 /(2 M+1)$ and the value of $\alpha$ for a given $n^{E 0}$ and $M$ is

\footnotetext{
${ }^{13}$ The relevant endowment heterogeneity is that of the initial $n^{E}$ rather than of the $n^{*}$ bloc members as the former make all the bloc's decisions, including those related to accession and to the bloc's negotiating position, i.e., they own the bloc.
} 


$$
\begin{aligned}
\alpha\left(n^{E 0}, M\right)=n^{E 0}-\int_{i=0}^{M} \frac{4}{(2 i+1)} d i & =n^{E 0}-2 \log (2 M+1), \\
\frac{\partial \alpha}{\partial M} & =-\frac{4}{2 M+1}<0, \frac{\partial^{2} \alpha}{\partial M^{2}}=\frac{8}{(2 M+1)^{2}}>0
\end{aligned}
$$

Since $\alpha$ falls with $M$, it follows from Equation (6) that implementing a migration policy raises the value of $n^{E}$. The next step is to determine the optimal value of $M$. Denoting the individual migration cost by $c$, the total benefit member states obtain from bloc formation in this case is,

$$
G(M) \equiv V(M)-c M ; \partial G / \partial M=\partial V / \partial M-c
$$

The value of $M, \tilde{M}$, which maximizes $G(M)$ at a value $\widetilde{G}(\tilde{M})=V(\tilde{M})-c \tilde{M}$, is given by the first-order condition which, with Equation (8), implies that $\frac{\partial \widetilde{G}}{\partial M}=\frac{\partial \widetilde{V}}{\partial M}$ $-c=\left(\frac{\partial \tilde{V}}{\partial \alpha}\right)\left(\frac{\partial \alpha}{\partial M}\right)-c,=-\left(\frac{4}{2 M+1}\right)\left(\frac{\partial \widetilde{V}}{\partial \alpha}\right)-c=0 .^{14}$ Thus,

$$
\tilde{M}=-\left[\frac{1}{2}+\frac{2}{c}\left(\frac{\partial \widetilde{V}}{\partial \alpha}\right)\right]>(=) 0 \Leftrightarrow c<(\geq)-4 \frac{\partial \widetilde{V}}{\partial \alpha}
$$

The likelihood that migration raises the value of the bloc falls with migration $\operatorname{cost} c$. Since $c>0$, a necessary condition for $M>0$ is $\partial \widetilde{V} / \partial \alpha<0$.

Denote the optimum bloc size in the presence (absence) of an accession fee by $\tilde{n}^{j}=\widetilde{n}^{*}\left(\widetilde{n}^{E}\right)$ and the optimum migration level by $\tilde{M}^{j}=\widetilde{M}^{*}\left(\widetilde{M}^{E}\right)$. Since $\widetilde{V}^{j}=\widetilde{n}^{j} \widetilde{B}^{j}$, it follows that $\frac{\partial \widetilde{V}^{j}}{\partial \alpha}=\widetilde{B}^{j} \frac{\partial \widetilde{n}^{j}}{\partial \alpha}+\widetilde{n}^{j} \frac{\partial \widetilde{B}^{j}}{\partial \alpha}$. Thus, from Equation (10), we have

$$
\widetilde{M}^{j}=-\left[\frac{1}{2}+\frac{2}{c}\left(\frac{\partial \widetilde{V}^{j}}{\partial \alpha}\right)\right]=-\left\{\frac{1}{2}+\frac{2}{c}\left[\widetilde{B}^{j}\left(\frac{\partial \widetilde{n}^{j}}{\partial \alpha}\right)+\widetilde{n}^{j} \frac{\partial \widetilde{B}^{j}}{\partial \alpha}\right]\right\}, j=*, E
$$

\footnotetext{
${ }^{14}$ It can be verified that the second-order condition holds.
} 
Since $\frac{\partial \widetilde{n}^{j}}{\partial \alpha}<0$ (see Equation (6) for $j=E$ and Equation (7) for $j=*$ ) and $\frac{\partial \widetilde{B}^{j}}{\partial \alpha}=-\frac{\partial C^{R}\left(\widetilde{n}^{j}\right)}{\partial \alpha}<0$ (see Equation (2)), it follows that $\partial V^{j} / \partial \alpha<0, j=E(*)$.

The impact of migration on the value of the bloc is

$$
\Delta G^{j}=\widetilde{G}^{j}\left(\tilde{M}^{j}\right)-G^{j}(0)=\left[\widetilde{V}^{j}\left(\tilde{M}^{j}\right)-c \tilde{M}^{j}\right]-V^{j}(0), j=*, E
$$

with the region's welfare maximized for $j=*$, though not for $j=E$. Under optimal migration, bloc size $\widetilde{n}^{E}\left(\widetilde{n}^{*}\right)$ in the absence (presence) of accession fee is represented by point $\mathrm{A}^{\prime}\left(\mathrm{E}^{\prime}\right)$ in the Figure. The average migration cost $z^{j}$ is given by $z^{j} \equiv c \tilde{M}^{j} / \widetilde{n}^{E}$, $j=E, *^{15}$ The average benefit in the absence of an accession fee is represented by point D' on the curve $B^{E}(\tilde{M})-z^{E}$. It is equal to $\widetilde{B}^{E}\left(\tilde{M}^{E}\right)-z^{E}=\mathrm{D}^{\prime} \mathrm{A}^{\prime}=\mathrm{C}^{\prime} 0$, with the curve starting at point $\mathrm{N}$ located below point $\mathrm{D}$ and with distance $\mathrm{DN}$ equal to $z^{E}$. The average benefit for the original members is represented by point $\mathrm{J}$ ' on curve $B^{*}(\tilde{M})-z^{*}$. It is equal to $\widetilde{B}^{*}\left(\tilde{M}^{*}\right)-z^{*}=\mathrm{J}^{\prime} \mathrm{E}^{\prime}=\mathrm{I}^{\prime} 0$.

From Equations (8) and (11), the value of $\alpha$ associated with $\tilde{M}^{j}$ is

$$
\widetilde{\alpha}^{j}=\tilde{n}^{j}-2 \log \left[\frac{-4}{c}\left(\frac{\partial \tilde{V}^{j}}{\partial \alpha}\right)\right]<(=)(>) \tilde{n}^{j} \Leftrightarrow \mathrm{c}<(=)(>)-4 \frac{\partial \tilde{V}^{j}}{\partial \alpha}, j=*, E
$$

It is clear from the analysis presented so far that bloc value $G$ depends on whether or not an accession fee and migration are present. For instance, in the absence of an accession fee, migration raises bloc members' average benefit from $B^{E}$ to $\widetilde{B}^{E}$ or from $\mathrm{DA}=\mathrm{C} 0$ to $\mathrm{D}^{\prime} \mathrm{A}^{\prime}=\mathrm{C}^{\prime} 0$. The increase in the value of the bloc $\Delta G^{E}=\widetilde{G}^{E}-G^{E}=\widetilde{G}^{E}-V^{E}$ is given by (C'0A'D'- C0AD) = C'D'A'ADC, which is equal to the region's welfare gain from the formation of the bloc. Under both migration and accession fee, the value of the bloc increases by an additional D'A'E'; i.e., the increase in bloc value relative to the absence of migration and accession fee is C'0E' $D$ ' - COAD.

\footnotetext{
${ }^{15}$ The denominator of $z^{j}$ is $\tilde{n}^{E}$ for both $j=E$ and $j={ }^{*}$ because all decisions - including those on the common negotiating positions are made by the original $\tilde{n}^{E}$ members, so that migration takes place exclusively between them.
} 
The findings in this section are summarized in Proposition 2.

Proposition 2: Denote international migration's impact on the value of the regional bloc by $\Delta G^{j}$, with $j=E(*)$ in the absence (presence) of an accession fee. The migration level that maximizes $\Delta G^{j}$ is given by Equation (11) and the associated heterogeneity level is given by Equation (13), leading to the following findings:

(i) The impact of migration on the value of the bloc $\Delta G^{j}$ increases with member states' level of heterogeneity and thus with regional negotiation costs.

(ii) The impact of migration on $\Delta G^{j}$ falls with migration costs.

(iii) The value of the bloc and its size are greater in the presence than in the absence of migration under a plausible cost of migrating between closely located countries, and so is the likelihood that $a$ bloc is formed.

(iv) As is the case in the absence of migration, the likelihood that a bloc is formed, the bloc's value and its size are greater with than without an accession fee in the presence of migration.

\section{South-South Migration and North-South Trade}

Section I described studies on the migration-trade relationship. This section examines this relationship in a Heckscher-Ohlin framework augmented with; (i) international negotiations between the North and the developing region's cooperative bloc, and (ii) South-South migration between the bloc's member states. It considers two alternative objectives pursued by bloc members in their international negotiations and examines implications for the migration-trade relationship. Each objective allows small states' production, consumption, and trade to be determined, which, together with the migration solution in Section III, closes the model. The first objective is to obtain a higher level of unilateral transfers. Their second, alternative objective is to obtain greater market access for their exports. The implications for the relationship between migration and trade are examined in Subsections A and B below, respectively. 


\section{A. Unilateral transfers}

Assuming that, in addition to being produced and consumed, goods $X$ and $Y$ are used as inputs in the production of regional and international negotiations as well as intra-bloc migration. These raise bloc size and the level of unilateral transfers, and raise the original bloc members' total benefit by, say, $\Delta G$. Homothetic preferences, as in Heckscher-Ohlin's model and constant relative prices imply constant income shares $s_{X}\left(s_{Y}=1-s_{X}\right)$ spent on $X(Y)$. Moreover, the fact that factor prices are given to the bloc members and to the bloc as a whole implies that the production of $X$ and $Y$ is given as well and is independent from the size of the transfers obtained.

A plausible assumption is that transfers are made in units of the donors' export good $Y$ (as with tied aid). Afterwards, migration and trade are substitutes, even in the extreme case where all negotiation-related expenditures are in units of $Y$. In the latter case, the (net) benefit $\Delta G$ is in units of $Y$ as well. Since a share $s_{X}$ of $\Delta G$ is spent on $X$, exports of $X$ fall by $s_{X} \Delta G$. Similarly, since a share $s_{Y}$ of $\Delta G$ is spent on $Y$, imports of $Y$ fall by (1$\left.s_{y}\right) \Delta G=s_{X} \Delta G$. Thus, migration and trade are substitutes. This holds a fortiori if a share of the expenditures is in units of $X$.

\section{B. Market access}

In this case, international migration raises the size of the regional bloc, thereby improving access for its exports through, say, a reduction in the North's import tariffs, resulting in an increase in the relative price of $X$, an increase (decrease) in the production of $X(Y)$, and an increase in North-South trade. Thus, migration and trade are complements in this case. ${ }^{16}$

The results obtained in this section are summarized in Proposition 3.

Proposition 3: The relationship between international migration and international trade depends on the object of the negotiations. Under negotiations for increased unilateral transfers (plausibly assumed to be provided in units of the donors' exportable good), migration and trade are substitutes. Under negotiations for increased market access,

\footnotetext{
${ }^{16}$ If the benefit is infra-marginal, as with an increase in a tariff quota that remains binding, trade increases as well but the relative export price is unchanged and so is output.
} 
migration and trade are complements.

\section{Conclusion}

This paper examined the issue of regional bloc formation among small developing states for the purpose of obtaining greater benefits from international negotiations in terms of negotiation costs and bargaining power rather than on the traditional traderelated arguments. The analysis was conducted within the framework of a HeckscherOhlin model, with small states benefiting from engaging in international negotiations as a bloc, but incurring a regional negotiation cost of achieving a unified position.

The main findings are as follows: (i) the size and welfare impact of the bloc depend on accession conditions. Selective membership without accession fee leads to an inefficiently small bloc because the marginal negotiating benefit is greater for existing bloc members than for new members and for non-member states. On the other hand, an accession fee maximizes the original bloc members' and the region's benefits by equalizing the marginal benefit for the three groups.

(ii) The bloc's size and its welfare impact increase with international negotiation costs and fall with the level of bloc members' heterogeneity.

(iii) The likelihood of intra-bloc migration raising initial bloc members' benefit increases with their heterogeneity and their geographic proximity. The value of the bloc might be negative in the absence of migration and positive under optimal migration.

(iv) Migration and trade are substitutes under negotiations for increased unilateral transfers, and are complements under negotiations for increased market access.

Several implications can be derived from the analysis presented in this paper. First, even if small states exhibit a similar trade structure and have little to gain from increased trade with their neighbors, they should nevertheless consider whether bloc formation might raise the benefits obtained from international negotiations for the bloc's member states, conditions which are more likely to prevail under a lower degree of heterogeneity among them. Second, they should consider whether such a bloc, if it is formed, would benefit from intra-bloc migration, the likelihood of which increases with the proximity between bloc members and with the degree of heterogeneity between them. Last, but certainly not the least, international negotiation costs must be important 
for small neighboring developing states to benefit from engaging in international negotiations as a bloc.

Received 6 June 2013, Revised 16 October 2013, Accepted 5 April 2014

\section{References}

Andriamananjara, Soamiely and Maurice Schiff. (2001), "Regional Groupings among Microstates", Review of International Economics 9(1): 42-51 (February).

Beine, Michel, Frédéric Docquier and Forthcoming. (2011), "Diasporas", Journal of Development Economics, Also World Bank, Policy Research Working Paper 4984.

Bollard, Albert, David McKenzie, Melanie Morten and Hillel Rapoport. (2009), "Remittances and the brain drain revisited: the microdata show that more educated migrants remit more," CID Working Paper 190, Center for International Development, Harvard University, December.

Byron, Jessica. (1994), "CARICOM in the Post-Cold War Era: Regional Solutions or Continued Regional Contradictions?", Institute of Social Studies, Working Paper No. 178, The Hague.

Ffrench-Davis, Ricardo. (1979), "Economía Internacional: Teoríasy Políticas para el Desarrollo", Fondo de Cultura Económica, México

IADB. (1995), "Economic Integration in the Americas: Periodic Note on Integration." http://www.iadb.org/ENGLISH/DEPARTMENTS/Int/intpub/nota/homepage.htm. and 2011.

Kugler, Maurice and Hillel Rapoport. (2007), "International labor and capital flows: Complements or substitutes?” Economics Letters 94(2): 155-162 (February).

López, Ramón and Maurice Schiff. (1998), "Migration and the Skill Composition of the Labor Force: The Impact of Trade Liberalization in LDCs", Canadian Journal of Economics 31 (2): 318-36. 
Markusen, James R. (1983), "Factor Movements and Commodity Trade as Complements". Journal of International Economics 14 (3-4): 341-356.

Martinez-Zarzoso, Inmaculada. (2000), "Gravity Model: An Application to Trade between Regional Blocs". Paper presented at the International Atlantic Economic Conference, Paris.

McKenzie, David and Hillel Rapoport. (Forthcoming), "Self-selection patterns in U.S.-Mexico migration: the role of migration networks". Review of Economics and Statistics.

Melo, Jaime de. (2007), "Migration, investissement et commerce: relation et implications politiques", Commentaires, Revue d'économie du développement 21(2): 37-47.

Melo, Jaime de and Artjoms Ivlevs. (2008), "FDI,the Brain Drain and Trade: Channels and Evidence", CEPR Discussion Paper 7002, CEPR.

Mora, Jorge and Edward J. Taylor. (2006), "Determinants of Migration, Destination and Sector Choice: Disentangling Individual, Household, and Community Effects"

C. Ozden and M. Schiff. (eds.), "International Migration, Remittances \& the Brain Drain”, Palgrave MacMillan and World Bank.

Mundell, Robert A. (1957), "International Trade and Factor Mobility", American Economic Review 47(3): 321-335.

Ozden, Caglar, Christopher R. Parsons, Maurice Schiff and Terry L. Walmsley. (Forthcoming), "Where on Earth Are They? Bilateral International Migration 1960200”, World Bank Economic Review

Rauch, James E. (1999), "Networks versus markets in international trade", Journal of International Economics 48(1): 7-35 (June).

Schiff, Maurice. (2010), "Small State Regional Cooperation, South-South and SouthNorth Migration and International Trade", Policy Research Working Paper 5297, World Bank(May).

Schiff, Maurice and L. Alan Winters. (1998), "Regional Integration as Diplomac", World Bank Economic Review (May)

Schiff, Maurice and L. Alan Winters. (2003), "Regional Integration and Development", London: Oxford University Press. 
te Velde, Dirk Willem. (2008), "Regional Integration, Growth and Convergence: Analytical Techniques and Preliminary Results", Mimeo. Overseas Development Institute. 